\title{
Posttranslational isoprenylation of tryptophan in bacteria
}

\author{
Masahiro Okada*, Tomotoshi Sugita and Ikuro Abe
}

\author{
Review \\ Address: \\ Graduate School of Pharmaceutical Sciences, The University of \\ Tokyo, Bunkyo-ku, Tokyo 113-0033, Japan

\section{Email:} \\ Masahiro Okada* - okadam@mol.f.u-tokyo.ac.jp \\ * Corresponding author

\section{Keywords:} \\ Bacillus subtilis; isoprenylation; post-translational modification; \\ quorum sensing; tryptophan
}

\author{
Beilstein J. Org. Chem. 2017, 13, 338-346. \\ doi:10.3762/bjoc. 13.37 \\ Received: 10 January 2017 \\ Accepted: 10 February 2017 \\ Published: 22 February 2017 \\ This article is part of the Thematic Series "Lipids: fatty acids and \\ derivatives, polyketides and isoprenoids". \\ Guest Editor: J. S. Dickschat \\ (c) 2017 Okada et al.; licensee Beilstein-Institut. \\ License and terms: see end of document.
}

\begin{abstract}
Posttranslational isoprenylation is generally recognized as a universal modification of the cysteine residues in peptides and the thiol groups of proteins in eukaryotes. In contrast, the Bacillus quorum sensing peptide pheromone, the ComX pheromone, possesses a posttranslationally modified tryptophan residue, and the tryptophan residue is isoprenylated with either a geranyl or farnesyl group at the gamma position to form a tricyclic skeleton that bears a newly formed pyrrolidine, similar to proline. The post-translational dimethylallylation of two tryptophan residues of a cyclic peptide, kawaguchipeptin A, from cyanobacteria has also been reported. Interestingly, the modified tryptophan residues of kawaguchipeptin A have the same scaffold as that of the ComX pheromones, but with the opposite stereochemistry. This review highlights the biosynthetic pathways and posttranslational isoprenylation of tryptophan. In particular, recent studies on peptide modifying enzymes are discussed.
\end{abstract}

\section{Introduction}

Posttranslational modification is the chemical modification of proteins after their translation from mRNAs to the corresponding polypeptide chains synthesized by ribosomes. Since a posttranslational modification generates a novel amino acid residue in ribosomally synthesized proteins consisting of the twenty normal amino acid residues, it increases the structural diversity of ordinary proteins. In addition, newly synthesized proteins lacking the modification often cannot perform the functions of the mature proteins. Therefore, posttranslational modifications dynamically regulate the biological activities of proteins. Novel modifications have been discovered over the last several decades, revealing numerous post-translational modification patterns, including isoprenylation [1,2]. This review will discuss the posttranslational isoprenylation of tryptophan in bacteria. In particular, this review will focus on current findings which have not been available at the time we published a review on this topic previously [3].

\section{Review}

Posttranslational isoprenylation of cysteine

Posttranslational isoprenylation is generally referred to as the farnesylation or geranylgeranylation of the thiol group of the 
C-terminal cysteine residue in peptides and proteins [4-7]. The isoprenylation of cysteine was first found in the peptide pheromones of basidiomycetous yeast [8-10]. Two peptide pheromones, tremerogen A-10 and tremerogen a-13, are secreted by the yeast-form haploid A-type and a-type cells of Tremella mesenterica, respectively (Figure 1A). Tremerogen A-10 is a decapeptide containing a hydroxyfarnesylated C-terminal cysteine methyl ester, whereas tremerogen a-13 is a tridecapeptide containing a farnesylated C-terminal cysteine (Figure 1B) $[9,10]$. Each pheromone causes the opposite type of cell to induce the reciprocal conjugation of the heterothallic cells, through the formation of a conjugation tube for mating. A structure-activity relationship study on tremerogen A-10 demon- strated that both the amino acid sequence and the hydrophobic side chain were essential for the initiation of the conjugation tube formation [11]. Soon thereafter, the consensus sequence for the isoprenylation of the cysteine in the precursor peptide was identified as the CaaX motif, in which "a" refers to an aliphatic amino acid and " $\mathrm{X}$ " refers to an appropriate amino acid, depending on the types of modifying enzymes (Figure 1C) [4-7]. Therefore, in the process of isoprenylated peptide and protein biosynthesis, the cysteine residue of the CaaX motif is isoprenylated by isoprenyltransferase, and then the last three amino acids are processed, often with methyl esterification of the resulting $\mathrm{C}$-terminal isoprenylcysteine. Considering the consensus sequence, a variety of organisms may produce

A)

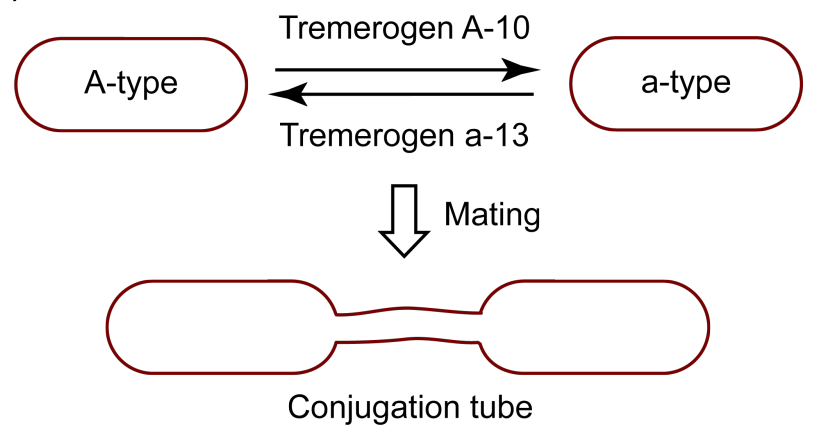

B)

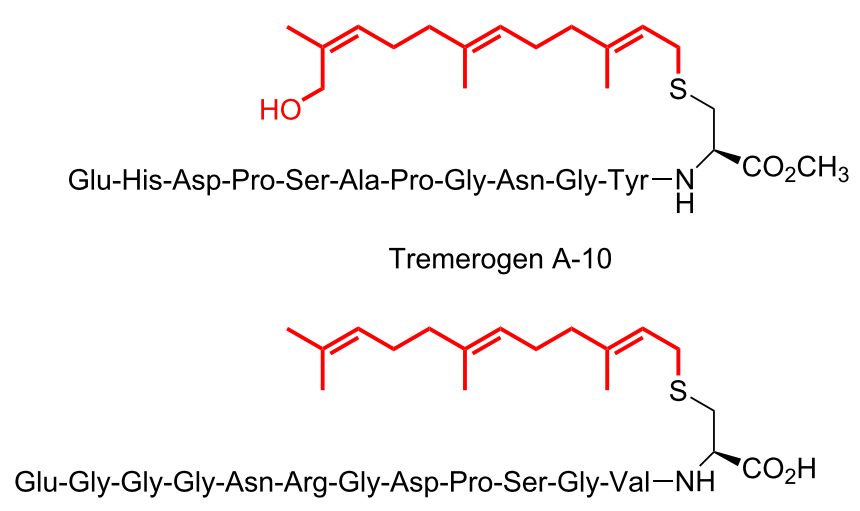

Tremerogen a-13

c)

Precursor

Tremerogen a-13

G-protein $\gamma 6$ (bovine)

K-Ras 4A (human)

Consensus sequence
Amino acid sequence

EGGGNRGDPSGVCVIA

ASENPFREKKFFCAIL EEKTPGCVKIKKCIIM

...........Caax
Modification

Farnesylation

Geranylgeranylation

Farnesylation

Figure 1: (A) Schematic representation of pheromone-induced conjugation tube formation for mating in Tremella mesenterica. (B) Chemical structures of tremerogens A-10 and a-13. The isoprenyl side chains are shown in red. (C) C-terminal amino acid sequences of the precursors of isoprenylated peptides and proteins. The CaaX motifs are shown in red. 
isoprenylated peptides and proteins. Subsequently, numerous isoprenylated peptides and proteins, such as G-proteins including the human oncogene product K-Ras, were identified from various organisms based on the consensus sequence (Figure 1C). Since the tumor growth induced by K-Ras is highly dependent on the farnesylation, the K-Ras farnesyltransferase has attracted keen attention as a target protein for anticancer therapy [12]. Posttranslational isoprenylation is now recognized as being universal in eukaryotes, and playing an essential role in protein functions.

\section{ComX pheromone}

In contrast to eukaryotes, cysteine isoprenylation has not been detected in prokaryotes. Posttranslational isoprenylation in prokaryotes was first found in a tryptophan residue of the quorum sensing pheromone from Bacillus subtilis, the ComX pheromone [13]. Quorum sensing is a specific gene expression system dependent on the cell density [14]. In terms of a competition for survival, the cell population density is one of the largest factors for microorganisms because of a high proliferation rate. In the quorum sensing process, bacteria constitutively secrete specific extracellular signaling molecules, called quorum sensing pheromones, to gather information about their cell population density [15-18]. Various phenomena are stimulated by an increase in the bacterial population density, or in other words, the concentration of the specific secreted pheromone. The ComX pheromone induces natural genetic competence under the control of quorum sensing in B. subtilis. Specifically, the ComX pheromone induces competent cell formation for DNA transformation at a high population cell density in B. subtilis $[19,20]$. In addition, the ComX pheromone promotes the production of surfactin A, a cyclic lipopeptide with antibiotic and biological surfactant activities (Figure 2A) [21,22]. Furthermore, the Com $\mathrm{X}_{\text {natto }}$ pheromone from B. subtilis subsp. natto contributes to the phenotypic characteristics involved in biofilm formation by $B$. subtilis subsp. natto, which is closely related to the Bacillus laboratory strains and renowned as the producer strain for the quite sticky, traditional Japanese food natto, made from fermented soybeans [23]. B. subtilis subsp. natto is obviously distinct from the other laboratory strains with respect to the biofilm formation. The biofilm mainly consists of the highly sticky poly- $\gamma$-glutamic acid ( $\gamma$-PGA) polymer (Figure 2B), and the Com $\mathrm{X}_{\text {natto }}$ pheromone activates $\gamma$-PGA biosynthesis in B. subtilis subsp. natto at nanomolar levels [24].

The ComX pheromones are oligopeptides, and their amino acid sequences and lengths vary widely among Bacillus strains (Figure 3A) [13,21,25]. However, each ComX pheromone possesses an invariant tryptophan residue as a single common denominator, and the tryptophan residue is isoprenylated with either a geranyl or farnesyl group at the gamma position to form tricyclic skeleton that bears a newly formed pyrrolidine, which is similar to proline (Figure 3A) [26-28]. The posttranslational modification of ComX pheromones with an isoprenoid plays an essential role for specific quorum sensing responses in B. subtilis and related bacilli [3]. Structure-activity relationship studies on the ComX $\mathrm{X}_{\mathrm{RO}-\mathrm{E}-2}$ pheromone derived from Bacillus strain RO-E-2, which is a hexapeptide with a geranyl-modified tryptophan residue, revealed that the exact chemical structure of the geranyl group and the absolute configurations of the tricyclic core scaffold were essential and more critical for its pheromonal activity than the amino acid sequence of the Com $X_{\text {RO-E-2 }}$ pheromone [29-32]. In addition, a previous study using a conditioned medium with Bacillus strains suggested that the chemical structure of the isoprenyl side chain is an influential factor of the group- (or species-) specific pheromonal activity [25]. Intriguingly, the same applies for group- (or species-) specificity in Gram negative bacteria because the chemical structure and length of the acyl side chain in acylhomoserine lactones, which are quorum sensing pheromones secreted by Gram negative bacteria, have a great effect on the group specificity (Figure 3B) $[33,34]$. Modifications of the lipophilic side

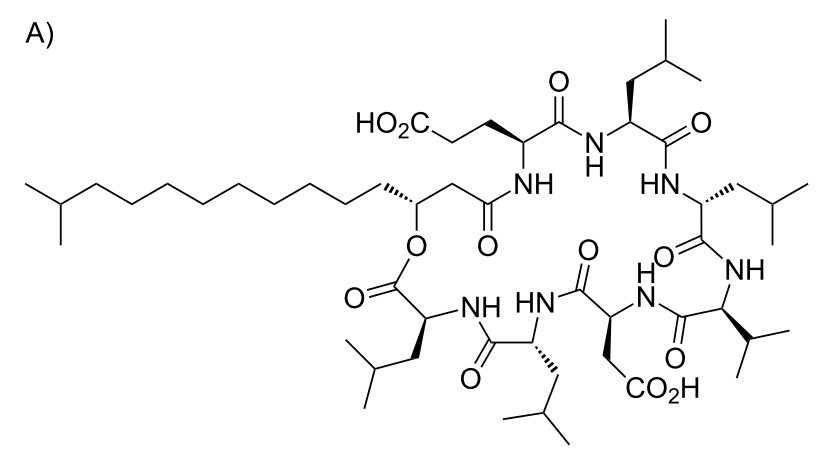

surfactin A
B)<smiles>CCC(O)C(=O)CCC1NC(C)OC1=O</smiles>

$\gamma-\mathrm{PGA}$

Figure 2: Chemical structures of $(A)$ surfactin $A$ and $(B)$ poly- $\gamma-$ glutamic acid. 
A)

\begin{tabular}{|c|c|c|}
\hline Bacillus strain & Amino acid sequence & Chemical structure of $\mathrm{W}$ \\
\hline 168 & ADPITRQWGD & \\
\hline RO-C-2 & TREWDG & \\
\hline Natto & KWPPIE & \\
\hline RO-E-2 & GIFWEQ & \\
\hline $\mathrm{RO}-\mathrm{H}-1$ & MLDWKY & \\
\hline RS-B-1 & MMDWHY & \\
\hline RO-B-2 & YTNGNWVPS & \\
\hline
\end{tabular}

B)

Vibrio harveyi Acyl homoserine lactone

Figure 3: (A) Two types of posttranslational isoprenylations of ComX variants. The modified tryptophan residues are colored blue. The isoprenyl side chains are shown in boldface and colored blue. (B) Chemical structures of acyl homoserine lactones. The acyl side chains are shown in boldface.

chain in quorum sensing pheromones are probably a common strategy to acquire group specificity in bacteria.

\section{ComQ}

Molecular genetic analyses of the natural competence of $B$. subtilis revealed that the com $Q X P A$ gene cluster was responsible for $B$. subtilis to induce the genetic competence involved in the secretion of the ComX pheromone (Figure 4A) $[13,21,25]$. ComQ, the first protein encoded in the cluster, functions as an isoprenyltransferase for the ComX peptide, which is encoded next in the cluster [35]. The downstream ComP is homologous to transmembrane histidine kinase, and ComA is homologous to a response regulator [36]. Therefore, the two proteins constitute the large family of two-component regula- tory systems widely found in bacteria. ComP becomes autophosphorylated in response to the secreted ComX signaling molecule as a receptor, and donates a phosphate group to ComA. The phosphorylated ComA subsequently transmits the signal for activating the surfactin synthase $\operatorname{srf} A$ operon and mediates the genetic competence in B. subtilis. ComQ lacks homology to cysteine isoprenyltransferases, tryptophan dimethylallyltransferases for cyanobactins $[2,37,38]$ or prenyltransferases for indole alkaloids [39-42]. However, ComQ shares some homology with farnesyl diphosphate (FPP) synthases and geranylgeranyl diphosphate (GGPP) synthases, which catalyze the condensation of isopentenyl diphosphate (IPP) with geranyl diphosphate (GPP) or FPP to form C5-extended isoprenyl diphosphates FPP or GGPP (Figure 4B) 
$[43,44]$. In the both typical diphosphate synthases, two aspartate-rich motifs containing "DDxxD" residues, in which $\mathrm{x}$ refers to any amino acid, are highly conserved. The two "DDxxD" motifs, named the first and second aspartate-rich motifs (FARM and SARM), function as the binding sites for the two substrates, GPP or FPP and IPP, through $\mathrm{Mg}^{2+}$ and play a crucial role in the FPP and GGPP syntheses. FARM is also conserved in ComQ, and a previous study demonstrated that the mutation of the first or fifth aspartate of FARM in ComQ to alanine resulted in the elimination of the downstream pheromonal signaling [21]. This result suggested that FARM of ComQ is necessary for the production of the ComX pheromone and possibly functions as a binding site for the extension substrate, GPP or FPP. In contrast to FARM, the amino acid residues corresponding to SARM in ComQ are quite different from those in the typical FPP and GGPP synthases (Figure 4B). Since only the second aspartate is preserved in the corresponding region of ComQ, the region is thus no longer aspartate-rich, and so hereafter it is referred to as a pseudo-SARM. A site-directed mutagenesis analysis of the ComQRO-E-2 from strain RO-E-2 with an in vitro geranylation reaction revealed that the lone-conserved second aspartate residue in the pseudo-SARM of ComQ is also critical for the isoprenylation activity, similar to the second aspartate residue in SARM in the FPP and GGPP synthases $[45,46]$. In addition, the first amino acid residue of the pseudo-SARM in ComQ, asparagine (or glycine), is crucial for the ComQ function. Particularly, the mutation from asparagine to aspartate drastically decreased the geranylation activity. In contrast, the last three amino acid residues of the pseudo-SARM in ComQ are replaceable, without the loss of ComQ function. Thus, for tryptophan isoprenylation the ComQ must have the sequence NDxxx (or GDxxx) in the pseudo-SARM. Although most FPP

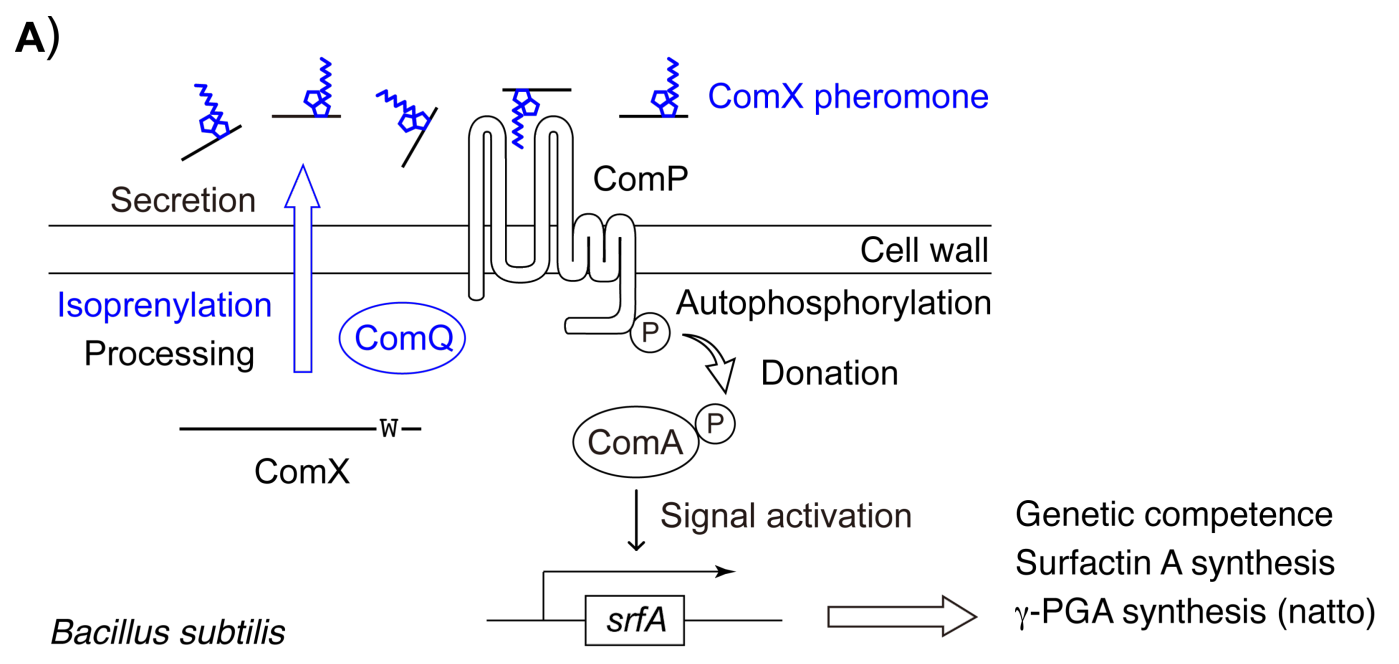

B)

\begin{tabular}{ccc} 
Enzyme & \multicolumn{2}{c}{ Amino acid sequence of aspartate rich motifs } \\
\hline ComQ_168 & SSDIMDDLEDEDN & GIIAQISGDYYVLL \\
ComQ_ROC2 & SSDIMDDLEDEDN & GIVAQISGDYHVLF \\
ComQ_Natto & SADIFDDIEDKDN & GIVEQIANDHYGLY \\
ComQ_ROE2 & AFDIFDDLEDEDN & GIIKQLENDYYGLV \\
ComQ_ROH1 & SFDIYDDLQDKDN & GIMSQIDNDYKGLF \\
ComQ_RSB1 & SFDIYDDLEDKDN & GIMSQIDNDYKGLF \\
ComQ_ROB2 & SFDIYDDLEDKDN & GIIAQIENDYQGLY \\
EcGGPPS & ATLLHDDVVDESD & GTAFQLIDDLLDYS \\
& FARM & SARM \\
\hline
\end{tabular}

Figure 4: (A) Schematic representation of the signal transduction cascade of quorum sensing stimulated by the ComX pheromone in $B$. subtilis. (B) Amino acid sequences of the aspartate-rich motif and the pseudo aspartate-rich motif in ComQ from seven Bacillus strains. Essential amino acid residues for function are shown in bold and colored blue. EcGGPPS is a geranylgeranyl diphosphate synthase derived from Escherichia coli ISC56. It's essential amino acid residues for function are shown in boldface, and the aspartate-rich motifs are underlined. 
and GGPP synthases possess the $\operatorname{DDxx}(\mathrm{D})$ amino acid sequence in the SARM, the sequence is unsuitable for the isoprenylation of tryptophan.

\section{ComX}

The ComX precursor peptide possesses 53 to 58 amino acid residues in six Bacillus strains, except for subsp. natto [25,26]. The tryptophan residue isoprenylated by ComQ is located at either the 3rd or 4th position from the C-terminal end, and the cleavage of the $\mathrm{N}$-terminal residues leads to the production of the mature ComX pheromone with six to ten amino acid residues (Figure 5). In most ribosomally synthesized and posttranslationally modified peptides (RIPPs), a conserved recognition motif in the $\mathrm{N}$-terminal leader region of the precursor peptide enables the enzymatic modification of the C-terminal core peptide, and then the leader amino acids are frequently cleaved [2]. However, there is no obvious sequence within the $\mathrm{N}$-terminal region of the ComX peptide for ComQ recognition, because the truncated C-terminal dodecapeptide of Com $\mathrm{X}_{\mathrm{RO}-\mathrm{E}-2}$ ([47-58]Com $X_{\text {RO-E-2, LSKKCKGIFWEQ) showed significant }}$ activity for geranyl modification by ComQRO-E-2, although the activity was approximately 10 -fold weaker than that of full length Com $\mathrm{X}_{\mathrm{RO}-\mathrm{E}-2}$ [47]. Among the twelve amino acid residues, the $\mathrm{N}$-terminal leucine residue and the modified tryptophan residue were the only conserved amino acids in the ComX variants. Therefore, a common consensus sequence for tryptophan isoprenylation does not seem to exist. In addition, the tryptophan residue modified with a geranyl group must be located at the $2 \mathrm{nd}$, $3 \mathrm{rd}$, or 4 th position from the C-terminal end of ComX $\mathrm{X}_{\mathrm{RO}-\mathrm{E}-2}$ for geranylation by $\mathrm{ComQ}_{\mathrm{RO}-\mathrm{E}-2}$, based on the in vitro reactions of $\mathrm{C}$-terminal sequence analogs with either a deletion of the two residues or an alanine extension at the C-terminal end. Therefore, the undecapeptide [47-57]ComX $X_{\text {RO-E-2 }}$ from the 47 th to the 57 th residues of the ComX $X_{\mathrm{RO}-\mathrm{E}-2}$, LSKKCKGIFWE, is the minimum substrate unit for geranylation by ComQ $\mathrm{RO}_{\mathrm{R}-\mathrm{E}-2}$. These results are consistent with the fact that the ComX pheromone variants among six Bacillus strains possess a modified tryptophan residue at the $3 \mathrm{rd}$ or 4th position from the $\mathrm{C}$-terminal end, except for the $\mathrm{ComX}_{\text {natto }}$ pheromone from subsp. natto. Unlike the six ComX pheromone variants, the Com $\mathrm{X}_{\text {natto }}$ pheromone possesses a modified tryptophan residue with a farnesyl group at the 5 th position from the $\mathrm{C}$-terminal end, which corresponds to the 54th residue in the 73 amino acid residues of $\mathrm{ComX}_{\text {natto }}$; namely, at the 20th position from the $\mathrm{C}$-terminal end. In addition, the $\mathrm{C}$-terminal amino acid residues of Com $\mathrm{X}_{\text {natto }}$ as well as the $\mathrm{N}$-terminal amino acid residues are processed to form the Com $\mathrm{X}_{\text {natto }}$ pheromone, corresponding to the 53 rd to 58 th residues of the $\operatorname{Com} \mathrm{X}_{\text {natto }}$ precursor peptide $[24,48]$. Although it is presently not clear which step occurs first, the farnesylation of the tryptophan residue or the truncation of the C-terminal amino acid residues, the posttranslational farnesylation was not necessarily limited to a tryptophan near the C-terminus, but also has occurred at an internal tryptophan residue of the precursor peptide.

\section{Kawaguchipeptin A}

Apart from the ComX pheromones, post-translational dimethylallylations of the tyrosine, threonine, serine, and tryptophan residues of cyclic peptides from cyanobacteria were reported [49-51]. The RiPPs derived from cyanobacteria, including dimethylallylated cyclic peptides, are called cyanobactins $[2,37,38]$. Although several cyanobactins exhibit significant biological activities, such as antibacterial and enzyme inhibitory properties, the actual biological role of prenylation in cyanobactins is still unknown at this time. Kawaguchipeptins A and $\mathrm{B}$ are members of the cyanobactin family and are macrocyclic undecapeptides with the cyclic amino acid sequence of [WLNGDNNWSTP]. They are produced by Microcystis aeruginosa NIES-88 (Figure 6) [52,53]. Kawaguchipeptin A contains one D-leucine and two prenylated tryptophan residues, while kawaguchipeptin B consists only of L-amino acid residues. Interestingly, kawaguchipeptin A possesses two dimethylallylated tryptophan residues, which are modified with a dimethylallyl group at the gamma position, resulting in the formation of

\begin{tabular}{|c|c|c|}
\hline Strain & Amino acid sequence of Com $X$ & (Underlined: ComX pheromone, $\mathrm{W}$ : isoprenylated) \\
\hline 168 & MQDLINYFLNYPEALKKLKNKEACLIGFDVQET & NDYYLADPITRQWGD \\
\hline RO-C-2 & MQDLINYFLSYPEVLKKLKNREACLIGFSSNET & NDYHLSSPTTREWDG \\
\hline Natto & MKH IDKI ISHLVNNPEAFDQFKNGNLTLLNINE & YAFEQGEVPRTSKWPPIEAISNFFEDDKRKSLI \\
\hline RO-E-2 & MKQDMIDYLMKNPQVLTKLENGEASLIGIPDKL & FNKKMTLSKKCKGIFWEQ \\
\hline $\mathrm{RO}-\mathrm{H}-1$ & MQEMVGYLIKYPNVLREVMEGNACLLGVDKDQS & KGLEIYSMLDWKY \\
\hline RS-B-1 & MQEMVGYLIKYPNVLREVMEGNACLLGVDKDQS & KGLEIYSMMDWHY \\
\hline RO-B-2 & MQEIVGYLVKNPEVLDEVMKGRASLLNIDKDQL & GGLQIYTNGNWVPS \\
\hline
\end{tabular}

Figure 5: Amino acid sequences of ComX from seven Bacillus strains. The sequences of the mature pheromones are underlined, and the isoprenylated tryptophan residues are shown in bold and colored blue. 
a tricyclic structure with the same scaffold as that of the ComX pheromones, but with the opposite stereochemistry [54]. The $K g p A$ to $G$ gene cluster was identified as encoding the kawaguchipeptins synthase in $M$. aeruginosa NIES-88 [55]. $\mathrm{KgpF}$ is a member of the ABBA prenyltransferase family, which shares a common structural motif known as the ABBA fold and exhibits some similarity to other dimethylallyltransferases for cyanobactins and prenyltransferases for indole alkaloids, but lacks similarity to cysteine isoprenyltransferases and ComQs [2,37-44]. Considering the in vitro prenylation analysis of $\mathrm{KgpF}$ together with other biosynthetic studies on prenylated cyanobactins, KgpF functions at the end of the biosynthesis, and recognizes two tryptophan residues in the precursor cyclic peptide to form kawaguchipeptin A. In contrast to typical posttranslational modifications, a specific amino acid motif adjacent to the core peptide sequence for directing $\mathrm{KgpF}$ is unlikely to be required. In addition, the prenylation reaction by $\mathrm{KgpF}$ does not seem to need a specific amino acid motif within the core cyclic peptide, because there is no similarity between the sequences surrounding the two tryptophan residues (PWL and NWS) in kawaguchipeptin A. Consistently, KgpF exhibits relaxed substrate specificity toward diverse tryptophan residues in peptides, as $\mathrm{KgpF}$ can even accept a single derivatized amino acid, Fmoc-tryptophan, as a substrate and mediate its regioselective and stereoselective dimethylallylation at the C-3 position of its indole ring.

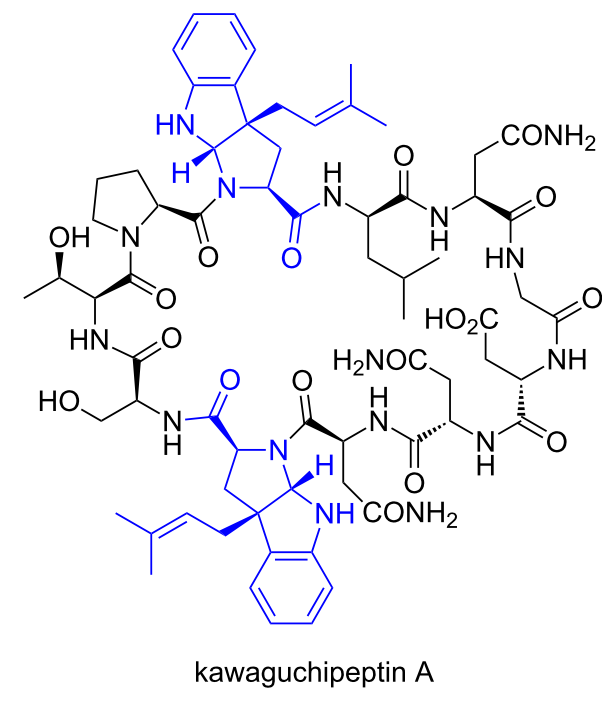

Figure 6: Chemical structure of kawaguchipeptin A. Dimethylallylated tryptophan residues are colored blue.

\section{Conclusion}

The posttranslational isoprenylation of tryptophan involving pyrrolidine ring formation was first discovered in a $B$. subtilis peptide pheromone, as a crucial modification for the pheromonal function. In addition, the discovery of the Com $\mathrm{X}_{\text {natto }}$ pheromone revealed that a tryptophan residue modified with an isoprenyl group is not always restricted to a location near the C-terminal end. The broad substrate tolerance of the modifying enzyme ComQ may attract attention as an enzyme engineering target for the synthesis of prenylated tryptophan derivatives. However, since the consensus sequences for tryptophan isoprenylation in the ComX precursor peptide and the ComX pheromone homologues have yet to be identified, it is presently considered that the post-translational geranylation or farnesylation of tryptophan is a special modification in several Bacillus species. In contrast, numerous peptides and proteins post-translationally modified with farnesyl or geranylgeranyl groups on the cysteine residues were identified in a variety of organisms. However, the isoprenylation was not considered to be universal at first. The isoprenylation of cysteine was also first found in peptide pheromones from a specific microorganism, as an essential modification for the pheromonal activity. Thus, it is conceivable that the posttranslational isoprenylation of tryptophan is actually widespread. Therefore, more research should be focused on the details and the diversity of the post-translational isoprenylation of tryptophan.

\section{Acknowledgements}

This work was supported in part by JSPS KAKENHI Grant Number 24688011 and a Grant-in-Aid for the Cooperative Research Project from Joint Usage/Research Center (Joint Usage/Research Center for Science-Based Natural Medicine). This work was also supported in part by Takeda Science Foundation, Kobayashi International Scholarship Foundation, and Suzuken Memorial Foundation.

\section{References}

1. Krishna, R. G.; Wold, F. Posttranslational Modifications. In Proteins-Analysis and Design; Angeletti, R. H., Ed.; Academic Press: San Diego, USA, 1998; pp 121-206.

2. Arnison, P. G.; Bibb, M. J.; Bierbaum, G.; Bowers, A. A.; Bugni, T. S.; Bulaj, G.; Camarero, J. A.; Campopiano, D. J.; Challis, G. L.; Clardy, J.; Cotter, P. D.; Craik, D. J.; Dawson, M.; Dittmann, E.; Donadio, S.; Dorrestein, P. C.; Entian, K.-D.; Fischbach, M. A.; Garavelli, J. S.; Göransson, U.; Gruber, C. W.; Haft, D. H.; Hemscheidt, T. K.; Hertweck, C.; Hill, C.; Horswill, A. R.; Jaspars, M.; Kelly, W. L.; Klinman, J. P.; Kuipers, O. P.; Link, A. J.; Liu, W.; Marahiel, M. A.; Mitchell, D. A.; Moll, G. N.; Moore, B. S.; Müller, R.; Nair, S. K.; Nes, I. F.; Norris, G. E.; Olivera, B. M.; Onaka, H.; Patchett, M. L.; Piel, J.; Reaney, M. J. T.; Rebuffat, S.; Ross, R. P.; Sahl, H.-G.; Schmidt, E. W.; Selsted, M. E.; Severinov, K.; Shen, B.; Sivonen, K.; Smith, L.; Stein, T.; Sussmuth, R. D.; Tagg, J. R.; Tang, G. L.; Truman, A. W.; Vederas, J. C.; Walsh, C. T.; Walton, J. D.; Wenzel, S. C.; Willey, J. M.; van der Donk, W. A. Nat. Prod. Rep. 2013, 30, 108-160. doi:10.1039/C2NP20085F

3. Okada, M. Biosci., Biotechnol., Biochem. 2011, 75, 1413-1417. doi:10.1271/bbb. 110087 
4. Clarke, S. Annu. Rev. Biochem. 1992, 61, 355-386. doi:10.1146/annurev.bi.61.070192.002035

5. Tamanoi, F.; Hrycyna, C. A.; Bergo, M. O., Eds. The Enzymes. Protein Prenylation Part A,, 1st ed.; Academic Press: San Diego, USA, 2011; Vol. 29.

6. Glomset, J. A.; Farnsworth, C. C. Annu. Rev. Cell Biol. 1994, 10, 181-205. doi:10.1146/annurev.cb.10.110194.001145

7. Zhang, F. L.; Casey, P. J. Annu. Rev. Biochem. 1996, 65, 241-269. doi:10.1146/annurev.bi.65.070196.001325

8. Kamiya, Y.; Sakurai, A.; Tamura, S.; Takahashi, N.; Abe, K.; Tsuchiya, E.; Fukui, S.; Kitada, C.; Fujino, M. Biochem. Biophys. Res. Commun. 1978, 83, 1077-1083. doi:10.1016/0006-291X(78)91505-X

9. Sakagami, Y.; Isogai, A.; Suzuki, A.; Tamura, S.; Kitada, C.; Fujino, M. Agric. Biol. Chem. 1979, 43, 2643-2645. doi:10.1271/bbb1961.43.2643

10. Sakagami, Y.; Yoshida, M.; Isogai, A.; Suzuki, A. Science 1981, 212, 1525-1527. doi:10.1126/science.212.4502.1525

11. Fujino, M.; Kitada, C.; Sakagami, Y.; Isogai, A.; Tamura, S.; Suzuki, A. Naturwissenschaften 1980, 67, 406-408. doi:10.1007/BF00405487

12. Winter-Vann, A. M.; Casey, P. J. Nat. Rev. Cancer 2005, 5, 405-412. doi:10.1038/nrc1612

13. Magnuson, R.; Solomon, J.; Grossman, A. D. Cell 1994, 77, 207-216. doi:10.1016/0092-8674(94)90313-1

14. Fuqua, W. C.; Winans, S. C.; Greenberg, E. P. J. Bacteriol. 1994, 176, 269-275. doi:10.1128/jb.176.2.269-275.1994

15. Bassler, B. L.; Losick, R. Cell 2006, 125, 237-246. doi:10.1016/j.cell.2006.04.001

16. Camilli, A.; Bassler, B. L. Science 2006, 311, 1113-1116. doi:10.1126/science.1121357

17. Williams, P.; Winzer, K.; Chan, W. C.; Cámara, M. Philos. Trans. R. Soc., B 2007, 362, 1119-1134. doi:10.1098/rstb.2007.2039

18. Dickschat, J. S. Nat. Prod. Rep. 2010, 27, 343-369. doi:10.1039/b804469b

19. Tortosa, P.; Dubnau, D. Curr. Opin. Microbiol. 1999, 2, 588-592. doi:10.1016/S1369-5274(99)00026-0

20. Hamoen, L. W.; Venema, G.; Kuipers, O. P. Microbiology 2003, 149 , 9-17. doi:10.1099/mic.0.26003-0

21. Bacon Schneider, K.; Palmer, T. M.; Grossman, A. D. J. Bacteriol. 2002, 184, 410-419. doi:10.1128/JB.184.2.410-419.2002

22. Tran, L.-S. P.; Nagai, T.; Itoh, Y. Mol. Microbiol. 2000, 37, 1159-1171. doi:10.1046/j.1365-2958.2000.02069.x

23. Jung, J.; Yu, K. O.; Ramzi, A. B.; Choe, S. H.; Kim, S. W.; Han, S. O. Biotechnol. Bioeng. 2012, 109, 2349-2356. doi:10.1002/bit.24524

24. Hayashi, S.; Usami, S.; Nakamura, Y.; Ozaki, K.; Okada, M. Biosci., Biotechnol., Biochem. 2015, 79, 1567-1569. doi:10.1080/09168451.2015.1032884

25. Ansaldi, M.; Marolt, D.; Stebe, T.; Mandic-Mulec, I.; Dubnau, D. Mol. Microbiol. 2002, 44, 1561-1573. doi:10.1046/j.1365-2958.2002.02977.x

26. Okada, M.; Sato, I.; Cho, S. J.; Iwata, H.; Nishio, T.; Dubnau, D.; Sakagami, Y. Nat. Chem. Biol. 2005, 1, 23-24. doi:10.1038/nchembio709

27. Okada, M.; Yamaguchi, H.; Sato, I.; Tsuji, F.; Qi, J.; Dubnau, D.; Sakagami, Y. Biosci., Biotechnol., Biochem. 2007, 71, 1807-1810. doi:10.1271/bbb.70245

28. Okada, M.; Yamaguchi, H.; Sato, I.; Tsuji, F.; Dubnau, D.; Sakagami, Y. Biosci., Biotechnol., Biochem. 2008, 72, 914-918. doi:10.1271/bbb.80006
29. Okada, M.; Sato, I.; Cho, S. J.; Suzuki, Y.; Ojika, M.; Dubnau, D.; Sakagami, Y. Biosci., Biotechnol., Biochem. 2004, 68, 2374-2387. doi:10.1271/bbb.68.2374

30. Okada, M.; Sato, I.; Cho, S. J.; Dubnau, D.; Sakagami, Y. Tetrahedron 2006, 62, 8907-8918. doi:10.1016/j.tet.2006.06.074

31. Okada, M.; Yamaguchi, H.; Sato, I.; Cho, S. J.; Dubnau, D.; Sakagami, Y. Bioorg. Med. Chem. Lett. 2007, 17, 1705-1707. doi:10.1016/j.bmcl.2006.12.070

32. Tsuji, F.; Kobayashi, K.; Okada, M.; Yamaguchi, H.; Ojika, M.; Sakagami, Y. Bioorg. Med. Chem. Lett. 2011, 21, 4041-4044. doi:10.1016/j.bmcl.2011.04.123

33. Zhang, R.-g.; Pappas, K. M.; Brace, J. L.; Miller, P. C.; Oulmassov, T.; Molyneaux, J. M.; Anderson, J. C.; Bashkin, J. K.; Winans, S. C.; Joachimiak, A. Nature 2002, 417, 971-974. doi:10.1038/nature00833

34. Geske, G. D.; O’Neill, J. C.; Miller, D. M.; Mattmann, M. E.; Blackwell, H. E. J. Am. Chem. Soc. 2007, 129, 13613-13625. doi:10.1021/ja074135h

35. Weinrauch, Y.; Msadek, T.; Kunst, F.; Dubnau, D. J. Bacteriol. 1991, 173, 5685-5693. doi:10.1128/jb.173.18.5685-5693.1991

36. Weinrauch, Y.; Penchev, R.; Dubnau, E.; Smith, I.; Dubnau, D. Genes Dev. 1990, 4, 860-872. doi:10.1101/gad.4.5.860

37. McIntosh, J. A.; Donia, M. S.; Schmidt, E. W. Nat. Prod. Rep. 2009, 26 537-559. doi:10.1039/b714132g

38. Czekster, C. M.; Ge, Y.; Naismith, J. H. Curr. Opin. Chem. Biol. 2016, 35, 80-88. doi:10.1016/j.cbpa.2016.08.029

39. Tello, M.; Kuzuyama, T.; Heide, L.; Noel, J. P.; Richard, S. B. Cell. Mol. Life Sci. 2008, 65, 1459-1463. doi:10.1007/s00018-008-7579-3

40. Yu, X.; Li, S.-M. Methods Enzymol. 2012, 516, 259-278. doi:10.1016/B978-0-12-394291-3.00005-8

41. Walsh, T. ACS Chem. Biol. 2014, 9, 2718-2728. doi:10.1021/cb500695k

42. Tanner, M. E. Nat. Prod. Rep. 2015, 32, 88-101. doi:10.1039/C4NP00099D

43. Wang, K.; Ohnuma, S.-i. Trends Biochem. Sci. 1999, 24, 445-451. doi:10.1016/S0968-0004(99)01464-4

44. Poulter, C. D. Phytochem. Rev. 2006, 5, 17-26. doi:10.1007/s11101-005-4887-1

45. Tsuji, F.; Ishihara, A.; Kurata, K.; Nakagawa, A.; Okada, M.; Kitamura, S.; Kanamaru, K.; Masuda, Y.; Murakami, K.; Irie, K.; Sakagami, Y. FEBS Lett. 2012, 586, 174-179. doi:10.1016/j.febslet.2011.12.012

46. Okada, M.; Ishihara, A.; Yamasaki, R.; Tsuji, F.; Hayashi, S.; Usami, S.; Sakagami, Y. Biosci., Biotechnol., Biochem. 2014, 78, 550-555. doi:10.1080/09168451.2014.891932

47. Tsuji, F.; Ishihara, A.; Nakagawa, A.; Okada, M.; Kitamura, S.; Kanamaru, K.; Masuda, Y.; Murakami, K.; Irie, K.; Sakagami, Y. Biosci., Biotechnol., Biochem. 2012, 76, 1492-1496. doi:10.1271/bbb.120206

48. Okada, M.; Nakamura, Y.; Hayashi, S.; Ozaki, K.; Usami, S. Bioorg. Med. Chem. Lett. 2015, 25, 4293-4296. doi:10.1016/j.bmcl.2015.07.083

49. Donia, M. S.; Ravel, J.; Schmidt, E. W. Nat. Chem. Biol. 2008, 4, 341-343. doi:10.1038/nchembio.84

50. McIntosh, J. A.; Donia, M. S.; Nair, S. K.; Schmidt, E. W. J. Am. Chem. Soc. 2011, 133, 13698-13705. doi:10.1021/ja205458h

51. Sardar, D.; Lin, Z.; Schmidt, E. W. Chem. Biol. 2015, 22, 907-916. doi:10.1016/j.chembiol.2015.06.014

52. Ishida, K.; Matsuda, H.; Murakami, M.; Yamaguchi, K. Tetrahedron 1996, 52, 9025-9030. doi:10.1016/0040-4020(96)00452-8 
53. Ishida, K.; Matsuda, H.; Murakami, M.; Yamaguchi, K. J. Nat. Prod. 1997, 60, 724-726. doi:10.1021/np970146k

54. Okada, M.; Sugita, T.; Akita, K.; Nakashima, Y.; Tian, T.; Li, C.; Mori, T.; Abe, I. Org. Biomol. Chem. 2016, 14, 9639-9644. doi:10.1039/C6OB01759B

55. Parajuli, A.; Kwak, D. H.; Dalponte, L.; Leikoski, N.; Galica, T.; Umeobika, U.; Trembleau, L.; Bent, A.; Sivonen, K.; Wahlsten, M.; Wang, H.; Rizzi, E.; De Bellis, G.; Naismith, J.; Jaspars, M.; Liu, X.; Houssen, W.; Fewer, D. P. Angew. Chem., Int. Ed. 2016, 55, 3596-3599. doi:10.1002/anie.201509920

\section{License and Terms}

This is an Open Access article under the terms of the Creative Commons Attribution License

(http://creativecommons.org/licenses/by/4.0), which permits unrestricted use, distribution, and reproduction in any medium, provided the original work is properly cited.

The license is subject to the Beilstein Journal of Organic Chemistry terms and conditions:

(http://www.beilstein-journals.org/bjoc)

The definitive version of this article is the electronic one which can be found at: doi:10.3762/bjoc. 13.37 